\title{
Case Study: Suicide Attempt by Intentional Ingestion of Chlormequat
}

\author{
Guanghua Yang1, Djemila Kechkeche2, Hafid Belhadj-Tahar3, Alexandre Verdu4, \\ Nouredine Sadeg4 \\ ${ }^{1}$ School of Medicine, Tongji University, Shanghai, China \\ ${ }^{2}$ Departement of Chemistry, University of Pierre et Marie-Curie, Paris, France \\ ${ }^{3}$ Bruker France, Marne La Valée, France \\ ${ }^{4}$ AFPreMed, Toxicology Research Group, Toulouse, France \\ Email: nouredine.sadeg@ch-pontoise.fr
}

Received 21 January 2015; accepted 9 February 2015; published 12 February 2015

Copyright (C) 2015 by authors and Scientific Research Publishing Inc.

This work is licensed under the Creative Commons Attribution International License (CC BY). http://creativecommons.org/licenses/by/4.0/

(c) (i) Open Access

\begin{abstract}
Chlormequat is a quaternary ammonium and choline chlorinated derivated is used as plant growth regulating agent. There are very few documented cases of poisoning in humans. We reported a case of non-fatal suicide attempt by chlormequat in France. A 34-year-old woman was admitted to hospital after deliberate consumption of plant growth regulator, C5 SUN, containing chlormequat chloride ( $460 \mathrm{~g} / \mathrm{L})$ and choline chloride $(320 \mathrm{~g} / \mathrm{L})$. Immediately, she developed symptoms of respiratory distress and a cardiac massage was begun by her father. In this case report, we described the method for an accurate and reliable screening of chlormequat which was based on the combination of Target Analysis powerful software and a high performance TOF-MS (Impact HD from Bruker). After forced diuresis, the kinetic of elimination of chlormequat is biphasic: vascular phase diffusion (half-life of $5.6 \mathrm{hr}$ ) followed by a phase of free elimination (half-life of $16.2 \mathrm{~h}$ ). Although chlormequat poisoning is clinically similar to that observed with anticholinesterase compounds, chlormequat chloride is not an acetylcholinesterase inhibitor. Chlormequat seems to be a weak substrat competitor for cholinesterase leading to acetylcholine accumulation and prolonged depolarization in muscular junction. Cardiac massage, artificial respiration and forced diuresis have significantly improved the prognosis of our patient.
\end{abstract}

\section{Keywords}

Chlormequat, Suicide, Poisoning, Diuresis, Toxicokinetic, LCMS

How to cite this paper: Yang, G.H., Kechkeche, D., Belhadj-Tahar, H., Verdu, A. and Sadeg, N. (2015) Case Study: Suicide Attempt by Intentional Ingestion of Chlormequat. Forensic Medicine and Anatomy Research, 3, 39-42. 


\section{Introduction}

Deliberate self-poisoning has become an increasingly common response to emotional distress in vulnerable persons, and it is now one of the most frequent reasons for emergency hospital admission. In rural zones, the substances most commonly used for self-poisoning are agricultural chemical products as pesticides [1]. Chlormequat chloride which is containing in C5 SUN is a plant growth regulator that belongs to the quaternary ammonium class of chemicals commonly referred to as pesticide. Chlormequat chloride or [(2-cloroethyl) trimethylammonium chloride] works through inhibition of a plant hormone's biosynthesis which is useful in regulating the growth characteristics of many plants [2]. This early blockage prevents the synthesis of numerous plant hormones needed for normal plant growth and development. The sequence of events leading up to death generally consists of inhibition of cholinesterase, acetylcholine accumulation, disruption of nerve function (centrally or peripherally), respiratory failure, and ultimately asphyxiation [3]. It hasn't been estimated the lethal dose in men. While fatalities due to poisoning are reported frequently, only three case reports are published regarding fatal chlormequat chloride intoxication. Two fatalities were due to deliberate ingestion where patient drank unknown quantities of chlormequat [4] [5] and the other one was due to accidental exposure where chlormequat was determined to be present in fluids and tissue [6].

In this view, we describe a case of non-fatal suicide attempt due to chlormequat intoxication by ingestion of C5 SUN composed by $460 \mathrm{~g} / \mathrm{L}$ of chlormequat chloride and $320 \mathrm{~g} / \mathrm{L}$ of choline chloride.

\section{Case Report}

\subsection{History of Present}

A woman of a 34-year-old was admitted to the emergency unit following intentional ingestion of C5 SUN for suicidal purpose following a family conflict. The woman presented both, cyanosis and consciousness disorders. She has a past psychiatric history and she was hospitalized for suicide attempt in July 2012 when she took an overdose of her medication (anti-depressive agents). According to his father present during the incident, immediately the symptoms began after consumption of chlormequat chloride and choline chloride. She suddenly lost consciousness and cyanosis appears leading to respiratory distress. For 15 minutes, her father performed an epigastric and thoracic cardiac massage causing emesis. During that time, she remained unresponsive but was breathing slowly. When firemen arrived, the patient had a circulatory activity without spontaneous ventilation.

On admission, vital signs revealed pulse rate of 85 beats/minute, blood pressure of 131/84 mmHg, respiratory rate of 15 per minute and his body temperature was $35.5^{\circ} \mathrm{C}$. The patient was set in artificial breathing after an orotracheal intubation. She required ventilator support for three days. She was treated with an antibiotic agent (Amoxicillin-Augmentin $^{\mathrm{TM}}$ ) and was given by infusion at the rate of $2 \mathrm{~g} / 6 \mathrm{~h}$. She was perfused by $500 \mathrm{~mL}$ of physiological serum to increase the diuresis. The patient was sedated by fentanyl (opiod analgesic) and midazolam (benzodiazepine) when signs of waking appeared. Response to the treatment was good and gradual improvement in biomarkers of inflammation was noticed (CRP and orosomucoid). Following recovery, she was evaluated by psychiatrist and revealed that ingestion of C5 SUN was an impulsive act due to poor social support from family. She exit the intensive care unit one week after her admission.

\subsection{Other Medical Examinations}

Her chest X-ray showed a right pulmonary alveolar infiltrate. A digestive investigation revealed an ulcerated esophagitis shallow and an erythematous gastric with minimal lesions. There were no neurological deficits and no cardiovascular disorders. Examination of other systems was normal. A medical examination at admission showed normal renal functions. Biological analyzes showed an increase of CPK $(195 \mu L)$ and LDH (506 $\mu \mathrm{L})$ likelyhood due to the effect of chlormequat chloride on the muscles. Furthermore a hypercalcemia, hyperglycemia (14.9 $\left.\mathrm{mmol} \cdot \mathrm{L}^{-1}\right)$, acidosis $\left(\mathrm{HCO}_{3}: 21.4 \mathrm{mmol} \cdot \mathrm{L}^{-1}\right)$ with hypoxia (FIO2 81 and PEEP 3) occurred during the admission assessment. There was also an increase in lipase $(189 \mu \mathrm{L})$. Cholinesterase activity was normal.

\subsection{Toxicological Analysis}

To measure and follow elimination of chlormequat, toxicological analysis were performed using a bench-top Ultra-High Resolution LC-MSMS system, Impact HD from Bruker Daltonics, France. LC-MSMS analysis was 
carried out on RSLC U30000. All chromatographic separation were achieved using an Acclaim ${ }^{\mathrm{TM}}$ RSLC C18 $2.2 \mu \mathrm{M} 2.1 \times 100 \mathrm{~mm}$ column. A RSLC U3000 autosampler was used to inject $10 \mu \mathrm{L}$ of extract into the LC-MS. Chromatographic separation was achieved using of two mobile phases; one consisting of $5 \mathrm{mM} \mathrm{NH}_{4}$ formiate in 0.01\% formic acid solution in water; and a second mobile phase is a mix of water/MeOH (90:10). The total run time was $20 \mathrm{~min}$ at a flow rate of $0.2 \mathrm{~mL} / \mathrm{min}$. Mass spectrometry detection was performed by a Bruker Impact $\mathrm{HD}^{\mathrm{TM}}$ with electrospray ionization (ESI) performed in positive and negative mode. The mass spectrometer was tuned and calibrated using Na-formiate and acetate salt clusters. Samples were screened using a full scan mode.

Chlormequat quantities were determinate using an external calibration procedure. Based on the integrated peak areas for the reconstructed ion chromatograms corresponding at the $122 \mathrm{~m} / \mathrm{z}$ (for chlormequat), a five-point calibration curve of relative response factor versus chlormequat concentration was established. Relative responses factors were calculated for each sample and the corresponding chlormequat concentration was determined from the calibration curve. Blood contents were analyzed for the intact chlormequat. The results of the analyses are presented in Figure 1. The concentration of chlormequat in the blood at $\mathrm{T}_{0}$ was found to be 5.105 mg/L. While the hours passed, quantity of chlormequat in the blood significantly decreases. At 12 h after ingestion of the product, the level was $0.828 \mathrm{mg} / \mathrm{L}$. This improvement was made possible by the forced diuresis.

\section{Discussion}

Chlormequat is a quaternary ammonium. With choline chlorinated derivative, there are used as plant growth regulating agent. Generally, acute cholinergic symptoms due to anticholinergic pesticide poisoning manifests within 24 to 72 hours due to accumulation of acetylcholine at muscarinic and nicotinic sites. The intermediate syndrome which manifest after 24 to 96 hours due to prolonged activity of acetyl choline at nicotinic receptors resulting in weakness of ocular, neck, limb and respiratory muscles [7]. In this case, symptoms of intoxication in the first quarter of an hour after ingestion of a plant growth regulator were a respiratory deficiency. At the end of his hospitalization, laboratory values have returned to normal. Chlormequat does not induce inhibition of the activity of the acetyl cholinesterase. It acts at the neuromuscular junction and mainly in the diaphragmatic muscle contributing to respiratory distress. The chlormequat seems to act as a partial agonist of the acetylcholine receptor and causing a prolonged endplate depolarization including the diaphragm [8]. This effect is bringing closer that of decamethonium or succenylcholine [9]. Chlormequat kinetics was followed, with vascular phase diffusion (half-life of $5.6 \mathrm{hr}$ ) and a phase of free elimination (half-life of $16.2 \mathrm{~h}$ ). Its action is maximal vascular phase "bolus effect" and fades after diffusion (Figure 1). We are the first to show the chlormequat's toxicokinetics.

As far as use of atropine is considered as antidote, its role remains controversial because chlormequat is not an anticholinesterase agent. Database from TOXNET [7] don't recommend the administration of atropine [7]. Nevertheless, few authors have reported to use neostigmine such as a treatment counter the effects of chlormequat ingestion. Bardale et al. suggested use the label of container mentions neostigmine as an antidote. Therefore it creates more confusion and needs further clinical studies to clarify the issue [4]. Neuromuscular junctions were blocked by doses of $1 \mathrm{mg} / \mathrm{kg}$ and this effect was counteracted by administration of $1 \mathrm{mg} / \mathrm{kg}$ of neostigmine [9].

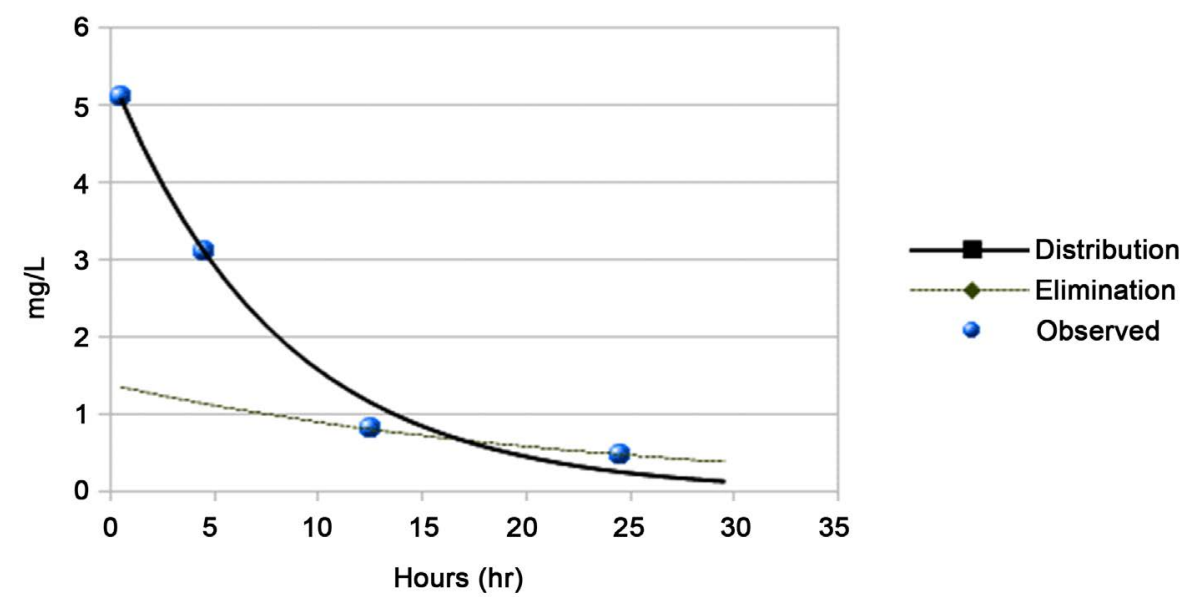

Figure 1. Concentration of chlormequat in blood by Impact HD Bench-Top QTOF. 
There is no antidote for chlormequat poisoning and treatment consisting of forced diuresis, earlier cardiac massage and artificial respiratory support, remains the only option. Aggressive primary decontamination with gastric lavage is required as early as possible. We did not assess the interest of activated charcoal in elimination of the chlormequat. Although chlormequat chloride poisoning resembles to the anticholinesterase agents's poisoning. However, chlormequat chloride is not an acetyl cholinesterase inhibitor. Chlormequat was believed to be weak substrat competitor for cholinesterase leading to acetylcholine accumulation and prolonged depolarization in the diaphragm muscular junction; and produce clinical features similar to excessive stimulation of cholinergic receptors throughout the central and peripheral nervous system.

Although the accidental or intentional ingestion of chlormequat is rare and to our knowledge only three such cases have been described in literature. This is the first case in France describe in the last 2 years. Winek et al. [6] reported a case of a 59-year-old man died approximately 5 hours after ingestion of a mouthful of an $11.8 \%$ chlormequat solution. Initially, the patient developed dizziness, profuse sweating, excessive salivation and visual disturbance. He was transferred to hospital where he was pronounced dead about 90 minutes after hospitalization. The death is a result of ventricular fibrillation which progressed to asystole. Autopsy findings showed pulmonary edema, coronary atherosclerosis, and of aorta injuries. Bardale et al. [4] reported also a case of fatal poisoning with plant growth regulator, chlormequat [4]. The patient was declared dead on arrival to hospital. Autopsy findings consist of congestion and edema of upper respiratory tract and esophagus, pulmonary edema and erosions of gastric mucosa. In all these cases, patients who accidentally or intentionally ingested chlormequat are dead. In our case, the patient survived thanks to the forced diuresis and the earlier cardiac massage. Indeed, following hour's rate of chlormequat dicreases such as it's described in Figure 1.

\section{Conclusion}

In conclusion, the favorable prognosis of our patients is primarily due to rapid support by cardiac massage and also monitoring of cardiopulmonary function in intensive care unit by forcing the elimination of the product by diuresis. Toxicokinetic is a usefulness tool to monitor elimination of chlormequat and prevent any rebound.

\section{References}

[1] Gunnell, D. and Eddleston, M. (2003) Suicide by Intentional Ingestion of Pesticides: A Continuing Tragedy in Developing Countries. International Journal of Epidemiology, 32, 902-909. http://dx.doi.org/10.1093/ije/dyg307

[2] Environmental Protection Agency Office of Pesticide Programs (2007) Reregistration Eligibility Decision for Chlormequat Chloride: United States. http://www.epa.gov/oppsrrd1/REDs/chlormequat_red.pdf

[3] Matsumura, F. (1974) Hazards to Man and Domestic Animals. In: Toxicology of Insecticides, Plenum Press, New York, 411-412.

[4] Bardale, R., Sonar, V. and Waghmare, S. (2012) Fatal Poisoning with Plant Growth Regulator. Journal of Punjab Academy of Forensic Medicine Toxicology, 12, 102-103.

[5] Freisleder, A., Bresserer, K. and Mallach, H.J. (1989) Suicide with a Supposedly Safe Plant Growth Regulator. Beitr Gerich Med, 47, 107-110.

[6] Winek, C.L., Wahbe, W.W. and Edelstein, J.M. (1990) Sudden Death Following Accidental Ingestion of Chlormequat. Journal of Analitical Toxicology, 14, 257-258. http://dx.doi.org/10.1093/jat/14.4.257

[7] (2014) TOXNET-Toxicology Data Network of National Library of Medicine. http://toxnet.nlm.nih.gov/cgi-bin/sis/search/a?dbs+hsdb:@term+@DOCNO+1541

[8] Liu, Y. and Dilger, J.P. (1993) Decamethonium Is a Partial Agonist at the Nicotinic Acetylcholine Receptor. Synapse, 13, 57-62. http://dx.doi.org/10.1002/syn.890130108

[9] FAO, WHO (1972) Chlormequat. "Monograph” from Central Medical. Department, American Cyanamid Co. Submitted to Joint FAO/WHO Meeting on Pesticide Residues. http://www.inchem.org/documents/jmpr/jmpmono/v072pr07.htm 
Scientific Research Publishing (SCIRP) is one of the largest Open Access journal publishers. It is currently publishing more than 200 open access, online, peer-reviewed journals covering a wide range of academic disciplines. SCIRP serves the worldwide academic communities and contributes to the progress and application of science with its publication.

Other selected journals from SCIRP are listed as below. Submit your manuscript to us via either submit@scirp.org or Online Submission Portal.
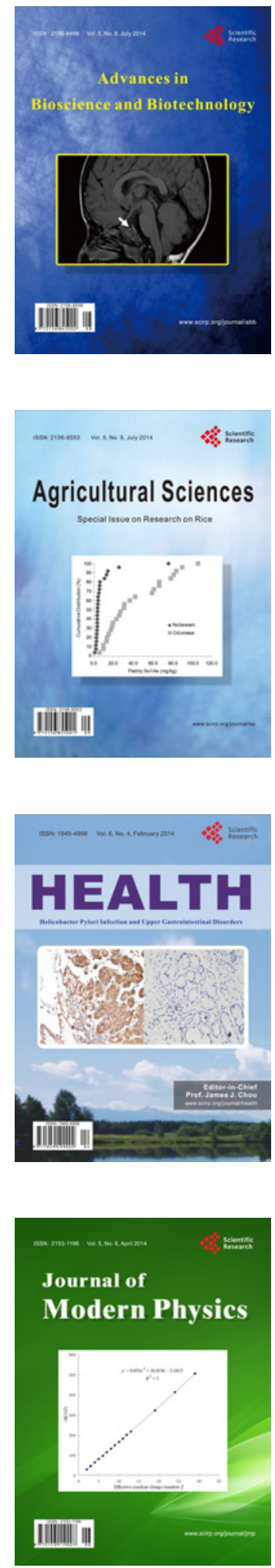
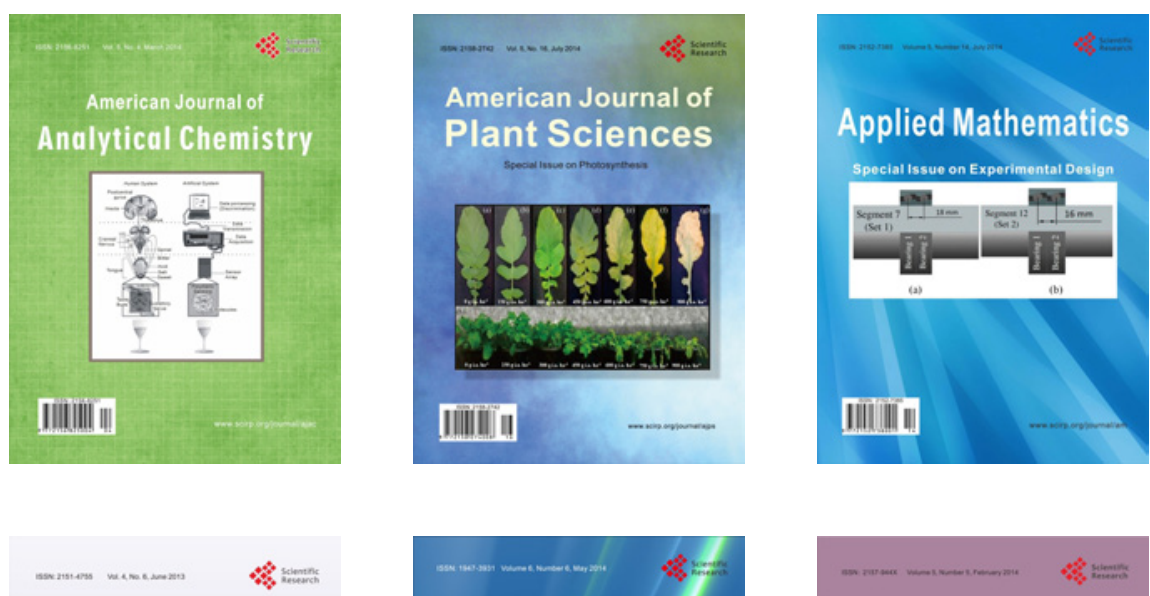

Creative Education
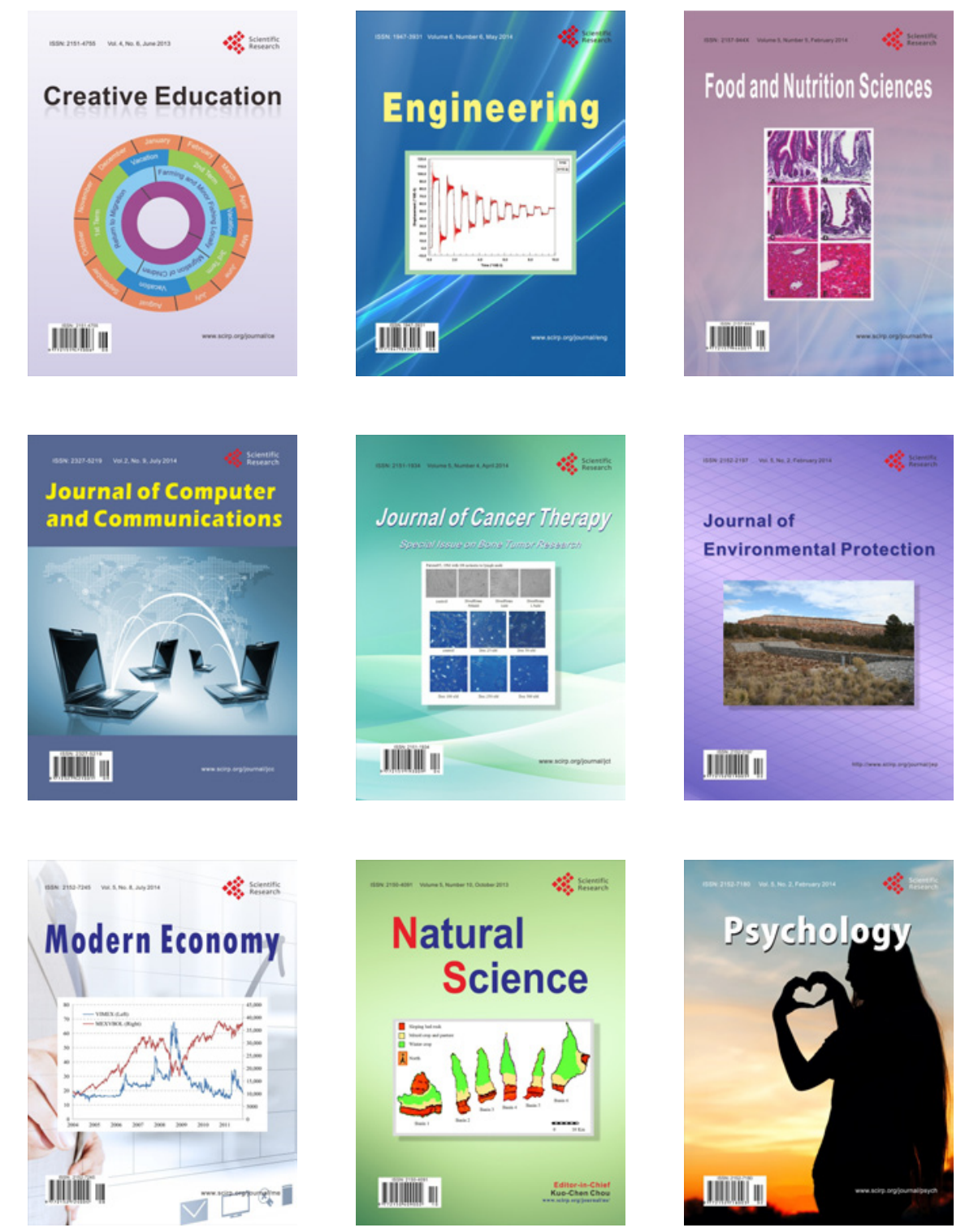